References:

[1] Ambrosino P. et al. Subclinical Atherosclerosis in Patients With Rheumatoid Arthritis. A Meta-Analysis of Literature StudiesThromb Haemost 2015; 113: 916-930.

[2] Avina-Zubieta JA et al. Risk of cardiovascular mortality in patients with rheumatoid arthritis: a meta-analysis of observational studies. Arthritis Rheum 2008; 59:1690-7.

[3] Protogerou A.D., Panagiotakos D.B., Zampeli E. Arterial hypertension assessed "out-of-office" in a contemporary cohort of rheumatoid arthritis patients free of cardiovascular disease is characterized by high prevalence, low awareness, poor control and increased vascular damage-associated "white coat" phenomenon. Arthritis Res Ther. 2013;15(5):R142.

[4] Panoulas V.F., Metsios G.S., Pace A.V. Hypertension in rheumatoid arthritis. Rheumatology (Oxford). 2008;47(9):1286-98.

[5] Hamamoto K., Yamada S., Yasumoto M. Et al. Association of nocturnal hypertension with disease activity in rheumatoid arthritis. Am J Hypertens 2016;29(3):340-7

Disclosure of Interest: None declared

DOI: 10.1136/annrheumdis-2017-eular.5382

\section{AB0365 HENOCH-SCHÖNLEIN PURPURA IN TUNISIAN ADULTS: MONOCENTRIC STUDY}

S. Hammami, M. Nasr, N. Sassi, R. Klii, M. Kechida, I. Kochtali. Internal medicine, University Hospital F Bourguiba Monastir, Monastir, Tunisia

Background: Henoch-Schonlein purpura (HSP) is a non thrombopenic leucocytoclasic acute systemic vasculitis of the small vessels with IgA-immun complex deposits, most commonly affecting the skin, joints, gastro-intestinal tract and the kidneys. It commonly affects the children aged between 4 to 10 years. The occurrence of HSP in adults is significantly less frequent with atypical profile, and more serious complications.

Objectives: Analysis of the clinical presentations, biological characteristics, treatment and evolutions of HSP in this population, compared with other tunisian and international studies.

Methods: This is a monocentric retrospective study using an operating record data from 30 adult patients aged 16 to 82 years hospitalized for HSP in Internal Medicine Department in Monastir university hospital between May 2005 to July 2015. Inclusion criteria's where those defined in 2006 by the European League Against Rheumatism (ELAR) and the Pediatric Rheumatology European Society (PRES) for the diagnosis of HSP.

Results: Thirty patients with Henoch-Schönlein purpura (18 women and 12 men) were included in the study. The mean age at onset of the disease was $48.80 \pm 18.77$ years (16 -82 years). The vascular purpura was the most frequent inaugural clinical manifestation (90\%). It was diffuse and necrotic in 3.3\% of cases. Cutaneous biopsy practiced in 26 cases (86.6\%), found leukocytoclastic vasculitis in 21 cases $(80.7 \%)$. Joint involvement was present in $80 \%$ : Inflammatory arthralgia in $56.6 \%$ and arthritis in $23,3 \%$. Sixteen patients (53.3\%) had gastro-intestinal involvement: Gastric and duodenal ulcers, occlusive syndrome, gastrointestinal bleeding and pancreatitis in $26,6 \%, 16,6 \%, 10 \%$ and $3,3 \%$ respectively. Eighteen patients $(60 \%)$ had renal involvement. Nephritic syndrome was observed in thirteen patients $(43,33 \%)$. Hematuria was objectified in 11 patients. Four patients had renal failure $(13,33 \%)$. The renal biopsy practiced in 4 cases, objectified IgA nephropathy in 3 patients and glomerulonephritis extra-capillary in 1 case. Interstitial lung disease with bilateral pleurisy was observed in a patient. A woman had a cerebral vasculitis. Corticosteroids were prescribed in 8 patients for gastrointestinal and renal impairment. Two patients received cyclophosphamide cures for cerebral vasculitis and severe digestive impairment. Anti-inflammatory drugs were prescribed in 9 cases. A favorable spontaneous development was observed in 9 patients. A recurrence was reported in 2 cases. One patient dead by severe sepsis.

Conclusions: HSP manifests in adult patients as a more severe and atypical disease with more relapses and more frequent and severe gastro-intestinal and renal disease. HSP in adults requires a sustainable monitoring and more aggressive treatment

References:

[1] José M et al Henoch-SchöNlein Purpura in Adults; Clinics. 2008 Apr; 63(2): 273-276.

[2] Danhua Shu et al. Risk factors of progressive IgA nephropathy which progress to end stage renal disease within ten years: a case-control study, BMC Nephrol. 2017; 18: 11

Acknowledgements: Department of Immunology, university Hospital, F Bourguiba Monastir Tunisia.

Disclosure of Interest: None declared

DOI: 10.1136/annrheumdis-2017-eular.4479

\section{AB0366 "I JUST WANT MY LIFE BACK": PHYSICAL FUNCTION AND FATIGUE ARE CRITICAL TARGETS FOR IMPROVING PARTICIPATION AND HRQL IN RHEUMATOID ARTHRITIS}

S.J. Bartlett $^{1,1}$, A. Sirois ${ }^{2}$, N. Chiarlitti ${ }^{2}$, M. Inceer ${ }^{2}$, M. Jones ${ }^{3}$, C.O. Bingham ${ }^{3}$. ${ }^{1}$ Medicine; ${ }^{2}$ Mcgill University, Montreal, Canada; ${ }^{3}$ Johns Hopkins, Baltimore, USA

Background: The primary goal of treatment for rheumatoid arthritis (RA) is to maximize health-related quality of life (HRQL) through symptom and damage control, and normalize function and participation in social and life activities. Although fatigue is recognized as one of the most debilitating symptoms of RA, little is known about how fatigue impacts participation.

Objectives: We hypothesized that fatigue, along with pain, mood, disease activity, and disability would be associated with reduced participation.

Methods: RA patients enrolled in an observational study at an academic center completed PROMIS measures assessing fatigue, physical function, mood (depression and anxiety), pain interference, sleep disturbance, and participation. RA clinical indicators were also collected at the visit. Variance inflation factors were examined to evaluate collinearity among variables. Covariates/confounders independently associated with participation included pain, mood (depression, anxiety), sleep, disease activity (CDAl), and physical function. Multiple regression models that did and did not include pain were compared using likelihood ratio tests with SPSS and R.

Results: Participants were mostly female (82\%) and white (83\%) with mean (SD) age of 56 (13) years; $24 \%$ had $\leq$ high school, $29 \%$ had RA $\leq 5$ years with $13 \%$ $\leq 2$ years, and $22 \%$ were disabled. Mean CDAl was 7.9 (7.8). Most were in CDAI remission $(n=56 ; 32 \%)$ or LDA $(n=67 ; 38 \%) ; 39(22 \%)$ were in MDA and $14(8 \%)$ in HDA. Mean PROMIS fatigue was 53.9 (10.0); fatigue increased across CDAI levels from 46.2 (8.6) in remission to 64.0 (9.6). Only those with HDA had mean sleep, depression or anxiety scores $>55$ (i.e., above population norms).

In the full model, fatigue, depression, CDAI, and physical function were significant independent predictors of reduced participation in social roles and activities $(F(2$, $162)=29.75, p<.001$, adjusted $\left.r^{2}=.55\right)$. Contrary to our hypothesis, pain was not associated with participation in univariate or multivariate models.

Conclusions: Our results suggest that in RA patients, high levels or fatigue are common; conversely, depression, anxiety, and sleep disturbance were elevated only in people with HDA. Disability and fatigue appear to have the greatest impact on participation in social roles and activities. RA treatments and interventions that attenuate fatigue and improve mood in people with active RA may improve their ability to participate in social and life situations restoring a sense of normalcy and improving HRQL.

Acknowledgements: Funding: PCORI IP2-PI0000737 and SC14-1402-10818, CIHR 312205.

Disclosure of Interest: None declared

DOI: 10.1136/annrheumdis-2017-eular.5597

\section{AB0367 THE PROPHYLACTIC EFFECT OF SULFASALAZINE AGAINST PNEUMOCYSTIS PNEUMONIA: AN ANALYSIS OF INCIDENCE FOR PNEUMOCYSTIS PNEUMONIA IN PATIENTS WITH RHEUMATOID ARTHRITIS IN JAPAN}

T. Nunokawa, N. Yokogawa, K. Shimada, S. Sugii. Department of Rheumatic Diseases, Tokyo Metropolitan Tama Medical Center, Fuchu-shi, Japan

Background: Cases with Pneumocystis pneumonia (PCP) have been reported in patients with rheumatoid arthritis, mainly treated with biologics. An experimental study in the mouse revealed that sulfasalazine enhances the clearance of the Pneumocystis organism from the lung (1). Furthermore, a case-control study with small sample size indicated possible preventive effect of sulfasalazine against PCP (2).

Objectives: The aim of this study is to clarify the prophylactic effect of sulfasalazine against PCP in patients with rheumatoid arthritis with a large sample size.

Methods: This retrospective study focused on all patients with rheumatoid arthritis seen between April, 2011 and October, 2016. at department of rheumatology, Tokyo Metropolitan Tama Medical Center. We investigated their demographics and medication, including corticosteroids, disease-modifying antirheumatic drugs and prophylactic drugs against PCP. The person-time at risk was calculated from prescription records. We compared the incidence during the period of follow-up in which the patients received sulfasalazine with that in which they did not received sulfasalazine. The incidents were assumed to follow a Poisson distribution and statistical analysis was performed using z-test.

Results: In the study period, 2,394 patients with rheumatoid arthritis were treated at our hospital. Among them, 24 patients received the treatment for PCP because the infection was diagnosed or was strongly suspected. All the cases developed the condition while they were not taking sulfasalazine. The incidence rate of PCP was significantly lower in the treatment period with sulfasalazine than that without sulfasalazine $(p<0.001)$.

Conclusions: Our study confirmed that sulfasalazine has a preventive effect against PCP in patients with rheumatoid arthritis.

\section{References:}

[1] Wang J, Gigliotti F, Bhagwat SP, George TC, Wright TW. Immune modulation with sulfasalazine attenuates immunopathogenesis but enhances macrophage- mediated fungal clearance during pneumocystis pneumonia. PLoS Pathog. 2010;6(8):59-60.

[2] Mizushina K, Hirata A, Hayashi N, et al. Possible preventive effect of salazosulfapyridine against development of Pneumocystis pneumonia in methotrexate-receiving patients with rheumatoid arthritis. Mod Rheumatol. 2015;7595(November):1-8.

Disclosure of Interest: None declared

DOI: 10.1136/annrheumdis-2017-eular.6083 